\title{
Tropical Animal Health and Production \\ Participatory identification of breeding objective traits and selection criteria for indigenous goat of the pastoral communities in Ethiopia \\ --Manuscript Draft--
}

Manuscript Number:

Full Title:

Participatory identification of breeding objective traits and selection criteria for indigenous goat of the pastoral communities in Ethiopia

Article Type:

Regular Articles

Keywords:

Borena; breeding program; Konso; flock ranking; traits of interest

Corresponding Author:

Tesfaye Getachew, PhD

International Center for Agricultural Research in the Dry Areas

Addis Ababa, ETHIOPIA

Corresponding Author Secondary

Information:

Corresponding Author's Institution:

International Center for Agricultural Research in the Dry Areas

Corresponding Author's Secondary

Institution:

First Author:

Tesfaye Getachew, PhD

First Author Secondary Information:

Order of Authors:

Tesfaye Getachew, PhD

A Haile, PhD

$\mathrm{T}$ Tessema

D Dea

Z Edea, PhD

B Rischkowsky, PhD

Order of Authors Secondary Information:

Funding Information:

CGIAR Research Program (CRP) on

Livestock and M-BoSs

Not applicable

Suggested Reviewers:

Solomon Abegaz Guangul, PhD

Researcher, Amhara Regional Agricultural Research Institute soabgu96@yahoo.com

Good technical capability and experience to work with goat community based breeding program in developing countries situation.

Opposed Reviewers: 
1

2

3

4

5

6

9 Abstract

10

11

12

13

14

15

16

17

18

19

20

21

\title{
Participatory identification of breeding objective traits and selection criteria for indigenous goat of the
} pastoral communities in Ethiopia

\author{
Getachew $\mathrm{T}^{1}$, Haile $\mathrm{A}^{1}$, Tessema $\mathrm{T}^{2}$, Dea $\mathrm{D}^{3}$, Edea $\mathrm{Z}^{4}$, Rischkowsky $\mathrm{B}^{1}$ \\ ${ }^{1}$ International Centre for Agricultural Research in the Dry Areas (ICARDA), clo ILRI 5689 Addis Ababa, Ethiopia. \\ ${ }^{2}$ Yabelo Agricultural Research Center, Yabelo, Ethiopia \\ ${ }^{3}$ Arba Minch Agricultural Research Center, Arba Minch, Ethiopia, \\ ${ }^{4}$ Department of Animal Science, Chungbuk National University, Cheongju, South Korea \\ Corresponding author: Tesfaye Getachew. E-mail: T.Getachew@ cgiar.org
}

Structured questionnaire, own-flock rankings and group discussions were undertaken to assess goat breeding practices and to identify traits of interest for genetic improvement of pastoral goats. Four pastoral villages in Ethiopia namely Jarso, Mesoya, Eleweya and Dharito were selected purposely based on their goat production potential and accessibility. A survey involving 70 households, and measurement of 199 goats in 4 villages was used. Data obtained from questionnaire, flock ranking and measurements were subjected to both qualitative and quantitative data analysis. In flock ranking experiment, goat owners were asked to choose the first three superior and a worst doe within their own flock. They were also asked to provide reason for ranking the animals. In addition, data on size traits, kid growth,

7 kid survival, reproduction traits, and milk yield were recorded for each doe. Large variation was observed between top and last ranked does in most of the traits and price: for example, in body weight ( $33.6 \pm 0.88 \mathrm{vs} 25.2 \pm 0.93 \mathrm{~kg}$ ), doe's kid survival $(92.1 \pm 4.01$ vs $59.6 \pm 4.48 \%)$ and doe's price $\left(1367 \pm 46.5\right.$ vs $833 \pm 46.9^{1}$ Ethiopian Birr). Mobility is practiced with defined and known pattern, therefore recruitment of a mobile enumerators for data recording would 1 assist in implementation of breeding programs. Breeding objective should emphasize mothering ability (kid growth

\footnotetext{
${ }^{1} 1$ USD $=28.4$ Ethiopian Birr
} 
22 and survival), milk yield of does and coat colour in all areas. Due to its good correlation with other traits like kid

23 growth and pre-weaning kid survival, considering milk yield alone as selection criteria or giving more weight for milk

24 yield in the breeding program could generate better genetic benefit. Setting-up breeding program should be based on

25 full participation and context of pastoralists.

26 Key words: Borena, breeding program, Konso, flock ranking, traits of interest

\section{Introduction}

28 Small ruminants in developing countries contribute to food security, income generation and socio-cultural benefits.

29 Ethiopia has huge small ruminant population estimated at 60.9 million heads (CSA, 2017). Goat production is an

30 integral component in pastoral systems of Ethiopia and plays a vital role for the livelihood of the community. Under

31 a challenging pastoral environment, goat has multiple roles in providing food (milk and meat) for the household (Bett

32 et al., 2009; Gebreyesus et al., 2013). In addition, they serve as source of income, socio-cultural benefits and as means

33 of expressing social prestige (Gebreyesus et al., 2013). Goats are especially important to women, children and the

34 aged, who are often the most vulnerable members of the society in terms of under-nutrition and poverty (Kosgey,

35 2004).

36 Breed improvement programs in developed countries are successful due to strong national breeding programs coupled

37 with high level of input, good technical capacity and infrastructure and good enabling situations. However, many

38 difficulties have been faced with the implementation of small ruminant breeding programs in developing countries

39 (Ayalew et al., 2003). Community-based breeding programs (CBBP) have been suggested as attractive options and

40 are being implemented in the highlands of Ethiopia (Haile et al., 2011) and other developing countries (Mueller et al.,

41 2015). These CBBPs have shown remarkable genetic progress in targeted production traits (Haile et al., 2018).

42 However, setting up and implementation of any breeding program in pastoral areas remain challenging. An earlier

43 attempt to implement CBBP in the pastoral system in the Afar region of Ethiopia was discontinued due to lack of

44 progress and a failure of adapting the approach to the challenging circumstances (Getachew et al., 2018). Irrespective

45 of the challenges; huge variation, adaptive genetic resource and high dependency of community on small ruminants

46 still justifies the importance of designing breeding programs fitting the system. Participatory way of breeding objective 
47 identification and understanding the context of local breeding practices is crucial for the success of such schemes.

48 Therefore, with the overall objective of designing and implementing CBBPs in pastoral areas we investigated the

49 breeding practices, breeding objectives and selection criteria adopted by pastoralists of different goat breeds.

\section{$50 \quad$ Materials and methods}

\section{Study sites and their description}

52 The study was carried out in Konso and Borena pastoral areas of southern Ethiopia. Two villages in each; Mesoya and

53 Jarso in Konso and Eleweya and Dharito in Borena district were selected purposely based on their goat potential,

54 representativeness of the pastoral system and their accessibility. The areas are characterized by low moisture, recurrent

55 drought and seasonal mobility of animals in search of feed and water. Goat production is considered as major farming 56 activity in both districts.

\section{Data collection}

Interview and group discussion

59 In each village, randomly selected goat owners were approached and interviewed using structured questionnaire. A 60 total of 70 owners of goat (19 in Jarso, 20 in Mesoya, 11 in Eleweya and 20 in Dharito) were interviewed in October

612017 (Table 1). Questionnaire were focused on obtaining information on understanding source of currently available

62 breeding animals, breeding practices, rank of important traits, mobility pattern and kid survival rate. Comprehensive

63 list of traits was provided to each owner and each of them was asked to confirm the importance of the trait and direction

64 of improvement they want. They were also asked if traits of importance were missed from the list. Then respondents 65 were asked to rank them. 
In addition, a focus group discussion was conducted in each village with 6-8 people (2-3 women). The discussions

71 were focused on identifying breed uniqueness, breeding knowledge, socio-cultural role of goat breeding, sire sharing,

72 mobility pattern, selection, culling and castration practices, fattening practices and goat production challenges.

\section{Own animal scoring/ranking for does}

74 Goat owners were asked to choose the first three superior and a worst doe within their own flock. They were also 75 asked to provide reason for ranking the animals. In addition, data on coat colour type, size and growth traits like, body 76 weight (BW), body length (BL), chest girth (CG), height at wither (HW), ear length (EL) and horn length (HL), 77 reproductive performances and mothering ability (doe parity, number of kids born so far, number of kids survived to 78 weaning age, kidding interval (KI) and kid growth (KG) score, milk yield (MY) score, body condition (BC) score 79 were recorded for each does. BC score assessed subjectively and recorded 1 to 5 as 1 very thin and 5 very fat. Preweaning kid survival (PWKS) was calculated for each doe as proportion of kids survived to weaning age to total

81 number of kids born in her life time. Twining rate (TR) was also calculated for each doe as a proportion of number of

82 kids born to doe parity. Owners provided information on MY performance for each doe as low, medium and high;

83 kidding interval as short, medium and long and doe's KG scored as slow, medium and fast for each animal based on 84 their memory. Economic value in terms of amount of money the owner is willing to pay (WTP) if he were to buy the 85 doe for breeding purpose were recorded for each doe.

\section{Data analysis}

87 All data were analyzed using R software. Cross table (crosstable) function in R using "gmodels" package was used to produce cross tabulations for qualitative data. Chi-square test was employed to assess independence between village and different variables like trait preferences, breeding buck availability and flock migration. Index based ranking was used to determine the relative importance of ranked traits. Index was calculated within district using the formula given by Zonabend König et al. (2016). 


$$
I_{j}=\sum_{i=1}^{3} r_{i} x_{i j} /\left(\sum_{j=1}^{7} \sum_{i=1}^{3} r_{i} x_{i j}\right)
$$

93 Where, $x_{i j}=$ is the number of respondents giving rank $i$ ( $i=1,2$ and 3$)$ to trait $j(j=$ seven trait categories include 94 growth, survival, reproduction, morphological manly coat colour, milk yield, behavioral traits). $r_{i}$ is the weight 95 corresponding to the rank in which weight of 3,2, and 1 assigned for the rank 1,2 and 3, respectively; aiming to give 96 the highest number for the most important trait.

97 Linear model ( $\mathrm{lm}$ ) function in R software was used to analyze quantitative data collected through questionnaire and 98 own flock ranking experiment fitting village (Jarso, Mesoya, Eleweya and Dharito) and doe rank (first, second, third 99 and last) as independent fixed factor and body condition score, litter size, kid survival proportion, willingness to pay, 100 body weight and body measurements) as dependent variables. Interaction between village and doe rank was removed 101 from the model as it was not significant $(P>0.05)$ in preliminary analysis. When the model was significant a post-hoc 102 test was employed using Tukey's honestly significant difference (HSD) tests, $\alpha=5 \%$ to compare least squares means 103 in a main effect.

104 Partial independence test using $\log$ linear model $(\log l \mathrm{~m})$ in $\mathrm{R}$ was used to test if village was independence of the 105 composite variables rank with kid growth score, rank with milk yield score and rank with kidding interval score. In 106 all cases, this model was not significant (results not shown here) so that analysis was done ignoring village. Then a 107 non-parametric, Kruskal-Wallis test was carried out to compare score of does for their performances (in their kid 108 growth, milk yield and kidding frequency) and rank of does. There was a very strong evidence of difference in the 109 mean score of kid growth, milk yield and kidding frequency of at least in one pair of ranking groups. Then pairwise 110 post-hoc analysis using Tukey distribution approximation were employed to compare mean values of different rank 111 levels.

112 Spearman's rank correlation of doe rank with thirteen different doe characteristics, doe BW, BC score, KI score, TR, 113 PWKS, KG score, MY score, doe monetary value in terms WTP, BL, CG, HW, EL and HL was employed using R. 114 Seven doe characteristics (KI score, KG score, MY score, PWKS, TR, CG and BW) were selected among the 13 based 
115 on their association level with doe rank and aiming to represent different traits. These traits were subjected to pair 116 wise correlation analysis.

\section{Results and discussion}

\section{Breeding and production practices}

\section{Source of breeding goats}

Generally, available goat flocks are results of long-term natural selection for adaptation to specific environment as well as selection by human being based on indigenous selection criteria. Birth, purchase and gift were found to be

122 important sources of building goat flock. There was no association $(\mathrm{P}>0.05)$ between location and the reasons for animal source. In this study, for majority $(80.6 \%)$ of the household's birth is the main way of acquisition of breeding does; among them, selection within the flock based on performance was the major source of currently available does for $54.8 \%$ of the respondent's while natural selection was the main source for $25.8 \%$ of the respondents (Table 2 ). Acquisition from market and gift from parents were the major source of current does for the 11.3 and $8.1 \%$ of the respondents, respectively. In Konso, source of buck is home grown, there is no purchase from outside. However, Borena community use bucks from other sources including those purchased from markets. This agrees with other study in southern Ethiopia by Tsedeke, (2007) who reported that birth has been the main way of flock building in sheep and goat and of bucks born in the flock has also been common in other pastoral areas of Borena and Shinele

131 (Gatew et al., 2017).

\section{Table 2.}

\section{Selection criteria and breeding knowledge}

134 Size of the animal, milk yield, frequent lambing and prolificacy and morphological traits, mainly coat colour of the 135 animal, were the frequently mentioned reasons to retain breeding does in the flock. Traits like big size, tall body frame, 136 long leg; and white and brown colours were considered when buying animals. Black is unwanted colour in all villages 137 and the price margin with black color (not preferred) for example in Konso area is 200-300 birr. Tera et al. (2013) 
also reported that black colored Horro sheep received a price discount of about $15 \%$ as compared to red coat colored sheep. Flock size per household in Konso is between 15-200. Male to female ratio on average is 1:10 however, in

140 some cases having larger number of breeding buck is common in Konso district. Breeding bucks are used for 2-3

141 years. There is no knowledge of inbreeding, they even encourage mating between relatives. pastoralists also reported

142 that small size, lambs growing horn immediately after birth, curled tail shape and diseases, particularly coenuruses,

143 could also be among the reasons for immediate culling of animals. Infertile does and short eared goats are also

144 subjected to culling in Borena area. Selection and culling criteria mentioned by pastoralists in this study are in general

145 agreement with other studies in smallholders and east Africa pastoralists (Gebreyesus et al., 2013; Marshall et al.,

146 2016; Gatew et al., 2017) and we are not aware of any other study reporting culling of lambs growing horn

147 immediately after birth. Pastoralists in the study areas believe that such incidence is considered as a curse and will

148 bring bad luck to the family unless culled immediately.

Socio-cultural role of goats

Goat have multiple socio-cultural roles in all areas including source of income, milk, and are slaughtered for home consumption, for guests and relatives, wife delivery, cultural and religious festivals. Goat are also slaughtered as

152 compensation when elders after conflict recommend that somebody is hurt; given as gift to help the poor and relatives; and they are bought for small money but can easily multiply and are sold to buy cattle. The same role of goats is also

154 reported for Issa community in eastern Ethiopia (Gebreyesus et al., 2013).

\section{Castration/fattening}

156 Fattening is a common practice in Konso while not in Borena. Fattening was done after breeding service (usually 157 after 2-3 years) and is done for a period of 6 months to 3 years. However, fattening was proceeded by castration. They 158 do castration after 2 years old. To start fattening they make sure that the animal has stopped growth, detected by the 159 smell the buck produces. Fattening is based mainly on grass but are sometimes given local brewery by-products. 


\section{Goat production challenges}

163 The major goat production challenges in both areas include disease (coughing, lung problem, liver fluke, coenurosis, 164 Contagious Caprine Pleuropneumonia and skin disease), feed shortage, both in quantity and quality. This agrees with 165 other studies in pastoral areas of Ethiopia (Loretto et al., 2015; Gatew et al., 2017). lack of appropriate markets has 166 also been identified as one of the challenges. The communities reported that they have local markets and buyers come 167 from different places but they believe the price they get for their animals is not attractive. Community animal health 168 workers could be trained to reduce some of the challenges associated with disease.

Table 3.

Breeding buck availability in the flock

171 There was no association $(\mathrm{P}>0.05)$ between study sites and breeding buck possession (Table 4). Majority of the goat 172 owner respondents (73.4\%) reported that they had at least one breeding buck while the remaining $26.6 \%$ of goat 173 owners reported that they had no breeding buck in their flock. Average number of breeding buck per household was 1743.09 with range of 1 to 15 (Figure 1). In all sites, all the currently available breeding bucks were born in the flock and 175 appeared as the result of selection by the owner for preferred traits.

176 Table 4.

177 Frequency distribution of number of buck available per household varied by location. It showed a wider range in 178 konso district; Jarso (0 to 15 bucks) and Mesoya (0 to 10 bucks) compared to Borena district which was found in the 179 range of 0 to 4 bucks per household (Figure 1). Irrespective of location, those without breeding buck reported that they used neighbors and relative buck in communal grazing land and watering points to mate their breeding does.

181 Average doe flock size per household in the study area is in the range of 9.3 to 15.1 (Netsanet, 2014; Gatew et al., 182 2017) and the majority (more than $90 \%$ ) had less than 25 does (Gebreyesus et al., 2012). This clearly indicated that 183 goat owners in Jarso and Mesoya keep surplus breeding bucks in their flock. Surplus breeding bucks ( 1:3 buck to doe ratio) was also reported in east Ethiopian pastoralists flocks (Gatew et al., 2017). Surplus bucks in the flock 
suggests that sufficient number of males are kept in the flock for mating purpose, however it affects the genetic progress due to less selection intensity. Wilson and Durkin (1988) recommended a male to female ratio of 1:25 for goats under traditional extensive systems. Thus, retaining best ones and culling surplus bucks in Jarso and Mesoya will be one the major intervention areas in implementing breeding program. Promoting profitable fattening technology and market linkage would be crucial to encourage pastoralists to sell unselected males. Unlike Jarso and Mesoya, availability of fewer bucks is an indication of over culling practice, which might be challenging in implementing community-based breeding program. Getting breeding buck from somewhere else at the beginning of the breeding programs; and devising mechanisms to retain best buck kids in the flock need to be considered in Eleweya and Dharito.

Figure 1.

\section{Mobility, flock mixing and buck sharing}

Majority (91\%) of goat owners reported that they move their goat temporarily to other places in search of feed and water mainly during the dry season. When drought hits (water shortage) they evaluate the situation about possible migration place and move. They have clear mobility pattern where they go and establish their own sites. Usually they migrate to river side. By the way, the communities have permanent settlement area (house) and part of the family takes the goats, spend part of the year and return with their animals when situations improve. Usually mobility is practiced once in a year; usually they migrate in January and come back home in April. Goat owners reported that all goat classes migrate except with very few goat owners who reported that kids and goat for fattening are maintained and managed in permanent places. Mating and kid rearing were continued in new places as it were practiced in permanent place. Indeed, carrying new born animals during migration and preparing new house for the new born kids were a common practice by many goat keepers.

There was significant association between location and flock mixing $(P=0.05)$ both in permanent and new settlement places (Table 5). Larger proportion (63 to 65\%) of the respondents in Jarso and Mesoya mentioned that they herded their flock separately, where as in other locations, Eleweya and Dharito most of them (66 to 74\%) reported that they mix their flocks. It has also been reported in other pastoral areas that majority of the communities herded their flock separately (Gebreyesus et al., 2013). Practices of sire exchange which is more common in sheep community-based 
breeding programs reported by Haile et al. (2011) should be promoted and reorganized with the keepers to reduce the negative effect of inbreeding. Proportion of goat owners mixing their flock increased during migration in all locations

212 (Table 5).

213 Number of goat flocks mixed together were 8, 4.5, 3.5 and 2.8 in permanent place and 8, 5.7, 3.6 and 7.3 in new place

214 for Jarso, Mesoya, Eleweya and Dharito, respectively. Mixing flock has usually been practiced among flocks of 215 neighbors and relatives. Same bucks used in permanent place also used for about $41 \%$ of the flocks during migration 216 time. However, the remining 59\% reported that a possibility of using new sires either from the same or different 217 community.

218 Table 5.

219 Test of association between interest in buck sharing and location was in the margin $(P=0.058)$. Among the respondents; 52.6, 50, 100 and 52.6\% in Jarso, Mesoya, Elewya and Dharito, respectively were interested to share their breeding buck to others. Willingness of sharing a buck is a very important element in designing breeding program as it helps to

222 increase buck accessibility, ease the transfer of genetic merit of best bucks to wider flocks as well as to reduce

223 inbreeding level (Haile et al., 2011). On the other hand, almost half of goat owners in Jarso, Mesoya and Dharito are not willing to share bucks (Table 6). It is important to understanding their reasons, thorough discussion and bringing

225 them on board is crucial for setting up community-based breeding programs.

Table 6.

Pre-weaning kid survival as perceived by pastoralists in different seasons

As expected survival proportion in good season were higher (78.4 to $96.1 \%)$ compared to survival values for kids born during the dry season (42.4 to $62.2 \%$ ). Better survival was observed in Mesoya and Jarso in both seasons and management type (Table 3). Kid survival was very low (42.4\%) in Dharito during the dry season when managed in permanent places. Animal movement during the dry season tended to improve kid survival in all villages (e.g. in Jarso 
increased from 42.4 to $56.1 \%$ ). Very low kid survival during the dry season observed in this study would have negative

234 effect on breeding program as it limits the number of candidate buck kids available for selection. Feed and water 235 shortage has mostly been reported as the major constraints limiting animal productivity in the pastoral areas 236 (Gebreyesus et al., 2012). Thus, urgent interventions are needed to minimize the harsh effect of dry season and thereby 237 reduce kid mortality and contribute to safe guarding the livelihood of pastoral communities. Successful pilot 238 development interventions like water development and range land management in Borena pastoral areas which 239 resulted in a year-round grazing (Homann et al., 2008) need to be implemented in a large scale. Additionally, traits 240 having positive association with kid survival like good milk yield and optimum birth weight (Oseni and Bebe, 2010) 241 need to be considered in the selection index.

\section{Traits for genetic improvement}

\section{$243 \quad$ Trait ranking}

244 Multiple traits with varied interest levels were identified as attributes of the goat owners would like to improve in the 245 future (Table 7). Four trait categories; traits related to size and growth, reproduction traits like (frequent kidding, early 246 age kidding and litter size), milk yield, and morphological traits mainly coat colour were highly ranked with very close 247 index values. Survival of kids ranked next to those traits. It is obvious that survival traits are masked by other traits 248 like fast growth and good milk yield of dam which has association with survival (Oseni and Bebe, 2010; Dossa et al., 249 20017). Some farmers, as observed during own flock ranking, preferred single kidding to have extra milk for the 250 family (e.g. in Jarso).

251 Association between ranking for trait and village was significant $(\mathrm{P}<0.05)$ for survival, morphological and behavioral 252 traits (Table 7). Relatively lower index value was observed in Jarso for survival trait compared to other locations. Coat 253 colour of the animal ranked high (second) in Eleweya and Dharito site indicating the importance of this trait in these 254 villages. Relatively larger index was observed in Mesoya for behavioral traits. Multiple breeding objectives of are 255 reflection of multiple roles goats play in the livelihood of pastoral communities. Similar traits of interest and multiple 256 breeding objectives have been documented in similar low input production systems (Bett et al., 2009; Ilatsia et al., 257 2012; Gebreyesus et al., 2013; Woldu et al., 2016). 


\section{Own flock ranking}

260 Body condition score, TR and PWKS influenced decision of owners in ranking their own does $(P<0.05)($ Table 8$)$.

261 Does with significantly lowest mean BC score (2.7) and having history of lowest PWKS in her life time (59.6\%) were

262 ranked as last by the owners. In contrary, does ranked first had the highest BC score. Does which ranked 1 to 3 had

263 higher kid survival performance ( 83.9 to $92.1 \%$ ) compared to does ranked last but there was no difference among the

264 top 3 does in kid survival. Similarly, does with higher LS were ranked as top. Does in Jarso and Mesoya had better

$265 P<0.05)$ body condition score compared to does in Eleweya and Dharito. However, pre-weaning kid survival was not

266 influenced by location $(P>0.05)$.

267 Table 8.

268 Ranking decision by owners for does was highly influenced by doe MY and her kid growth $(P<0.05)$. According to

269 the goat owner's perception those does which rank first produce more milk and their kids grow fast compared to third

270 and last ranked does (Table 9). However, there was no association between kidding interval score and doe ranking

$271(P>0.05)$.

272 Table 9

274 Size, morphological traits like BW and linear body measurements and price of does were also influenced $(P<0.05)$ by 275 doe rank and village except for horn length which has not affected ranking decision. Does ranked as last had lowest

276 value compared to the first, second and third ranked animals. Observed variation between top and last ranked does in 277 size (Table10) indicated the existence of huge within flock variation which would be exploited through structured 278 breeding program. For example, does chosen as first rank were on average $8.4 \mathrm{~kg}$ heavier than last ranked does. Goats 279 in Jarso was lighter in body weight and smaller in size $(P<0.05)$ compared to goats in other locations. Pastoralist were 280 willing to pay higher $(P<0.05)$ price for the first ranked does compared to others, and there was no difference in WTP 
281 between rank 2 and 3. Pastoralists expressed their WTP 64.1\% more for first ranked, 37.4\% for third ranked does than 282 for the last ranked does (Table 10). Such significant difference between best and worst ranked does in size, BW and 283 WTP was also reported in Red Massai and Dorper sheep in Kenya (Zonabend König et al., 2016).

Table 10 .

Correlation of doe rank with other traits

Most of the doe size, production, reproduction and morphological traits considered in this study had positive association but with varied level with the rank of does given by the owner (Table 11). Maternal traits like MY of does and growth of kids had consistently high correlation with doe rank in all locations. Twining rate had positive association with rank of does in Jarso and Eleweya $(P<0.001)$ whereas no association $(P>0.05)$ in Mesoya implies twinning is not a preferred trait in Mesoya. Association of BW and linear body measurements with doe rank is not consistent across locations. All measurements had significant association with doe rank particularly in Jarso and Eleweya village. Ear and horn length had positive $(P<0.05)$ association with doe rank in Jarso only. Large ear and horn is preferred by the community in Jarso.

Table 11.

\section{Correlation among selected traits}

Does with good twining rate had positive association with larger size and better milk yield $(\mathrm{P}<0.05)$. Pre-weaning kid

297 survival was positively associated with KG, size measurements and MY of its dam. Positive association between lamb 298 growth and survival were also reported in Menz sheep (Getachew et al., 2015). To ensure success of breeding program 299 in small holder low input system, traits to be considered in selection program should be few and easy to measure 300 (Sölkner et al., 1998). Positive relationship among TR, size traits like KG, doe size and doe body measurements and 301 doe milk yield observed in this study suggested that selection index considering few among the list would suffice. 302 Highest correlation coefficient between doe milk yield and rank (0.69) and doe's fast kid growth and doe rank (0.72) 303 was found in this study (Table 12). Milk yield had also good ( $\mathrm{r}=0.19$ to 0.78$)$ and significant $(P<0.05)$ correlation with 304 KI, TR, KPWS, CG and BW. The highest correlation found between MY and KG score and many other traits suggests 
that using MY as selection criterion is the most promising option to ensure reasonable kid growth and better kid survival. In agreement to this, significant and positive genetic progress has been achieved for number of kids survived to weaning age and weaning weight in the Egyptian Nubian sub-tropical goat breed when selection was made based on total milk yield (Afoul-Naga et al., 2012). Castañeda-Bustos et al., (2014) also found milk yield as one of the most important indirect prediction of real production life of goats in the US. Thus, due to its higher association with top ranked does and good correlation with other traits found in this study, and moderate to high heritability (Aboul-Naga et al., 2012; Castañeda-Bustos et al., 2014) and significant contribution of milk as staple food (Gebreyesus et al., 2013) inclusion of milk yield alone or giving more weight for milk yield in the breeding program could generate better genetic benefit. Recurrent drought in pastoral areas and low survivability of kids during the dry season justifies the importance of considering adaptation trait in the breeding program. However, measuring adaptation traits remain challenging and selection for indirect associated traits like milk yield and higher birth weight in the given environment will be more feasible and practical way. Two stages selection; selection based on records and participation of the community to approve selected animals based on their preference (Haile et al., 2011) is important to accommodate pastoralists preference of morphological characters. (below diagonal) useful tool in understanding the production situation and identifying key traits of interest for genetic improvement. Flock mobility is practiced in well-defined pattern and therefore, recruiting enumerator/s willing to move with flocks would likely address problem of data collection during mobility time. Thus, strategy to identify kids with top estimated breeding values at early age and sustain them (e.g. through better management) is crucial to minimize loss of best genotypes through kid mortality. Size traits, mothering ability (kid growth and survival), milk yield and coat colour

327 in varied level were identified as major traits to be improved in all sites. Considering milk yield alone as selection criteria or giving more weight for milk yield in the breeding program could generate better genetic benefit. Organizing different mating groups and arrange buck sharing system would help to increase buck accessibility as well as speed up genetic progress by allowing use of few top ranked bucks. Training of the community about mating system, buck sharing and effect of inbreeding is recommended. 
The authors are grateful to CGIAR Research Program (CRP) on Livestock and M-BoSs project for funding this research. We are grateful for pastoralists and staff of research and development agents who participated in data 335 collection.

\section{Conflict of interest}

The authors declare that they have no conflicting interests.

\section{References}

Aboul-Naga, A.M., Hamed, A., Shaat, I., Mabrouk, M.M.S., 2012. Genetic improvement of Egyptian Nubian goats as sub-tropical dairy prolific breed. Small Rumin. Res. 102, 125-130.

Ayalew, W., Rischkowsky, B., King, J.., Bruns, E., 2003. Crossbreds did not generate more net benefits than

Bett, R C, Kosgey, I S, Kahi, A K, Peters, K J. 2009. Analysis of production objectives and breeding practices of dairy goats in Kenya. Trop. Anim. Health Prod. 41, 307-320.

Castañeda-Bustos, V., Montaldo, H., Torres-Hernández, G., Pérez-Elizalde, S., Valencia-Posadas, M., Hernándezopportunities for improvement 49-57. practices and phenotypic characteristics of indigenous goat populations in Ethiopia. African J. Agric. Res. 12, 2729-2741. 
Gebreyesus, G., Haile, A., Dessie, T., 2013. Breeding scheme based on community-based participatory analysis of local breeding practices, objectives and constraints for goats around Dire Dawa, Ethiopia. Livest. Res. Rural Dev. Rural Dev. 25.

Gebreyesus, G., Haile, A., Dessie, T., 2012. Participatory characterization of the Short-eared Somali goat and its production environment around Dire Dawa, Ethiopia. Livest. Res. Rural Dev. 24.

Getachew, T., Gizaw, S., Wurzinger, M., Haile, A., Rischkowsky, B., Okeyo, A.M., Sölkner, J., Mészáros, G., 2015. Survival analysis of genetic and non-genetic factors influencing ewe longevity and lamb survival of Ethiopian sheep breeds. Livest. Sci. 176.

Getachew, T., Haile, A., Rischkowsky, B., 2018. How to tailor community based breeding programs for small ruminants to pastoral production systems Challenges in adopting successful breeding program. Proc. World Congr. Genet. Appl. to Livest. Prod. Genetic ga, 858.

Haile, A., Gizaw, S., Getachew, T., Rischkowsky, B., 2018. Challenges in small ruminant breeding programs and resulting investment priorities in Ethiopia. Proc. World Congr. Genet. Appl. to Livest. Prod. Genetic ga, 475.

Haile, A., Wurzinger, M., Mirkena, T., Duguma, G., Mwai, O., Rischkowsky, B., 2011. Guidelines for Setting up Community-based Sheep Breeding Programs in Ethiopia. ICARDA - tools and guidelines. ICARDA, Aleppo; Syria.

Homann, S., Rischkowsky, B., Steinbach, J., 2008. The effect of development interventions on the use of indigenous range management strategies in the Borana lowlands in Ethiopia. L. Degrad. Dev. 19, 368-387.

Ilatsia, E.D., Roessler, R., Kahi, A.K., Piepho, H.P., Zárate, V., 2012. Production objectives and breeding goals of Sahiwal cattle keepers in Kenya and implications for a breeding programme. Trop. Anim. Health Prod. 44, $519-530$.

Kenfo, H., Mekasha, Y., Tadesse, Y., 2018. A study on sheep farming practices in relation to future production strategies in Bensa district of Southern Ethiopia 865-874. 
Kosgey, I.S., 2004. Breeding objectives and breeding strategies for small ruminants in the tropics. PhD Thesis, Animal Breeding and Genetics Group, Wageningen University.

Lorato, Y., Ahmed, K.M., Belay, B., 2015. Participatory Characterization of the Woyto-Guji Goat and Its Production Environment around Northern Omo, Ethiopia. J. Angriculture Nat. Resour. Sci. 2, 455-465.

Marshall, K., Mtimet, N., Wanyoike, F., Ndiwa, N., Ghebremariam, H., Mugunieri, L., Costagli, R., 2016. Traditional livestock breeding practices of men and women Somali pastoralists: trait preferences and selection of breeding animals $133,534-547$.

Mirkena, T., 2010. Identifying breeding objectives of smallholders / pastoralists and optimizing community-based breeding programs for adapted sheep breeds in Ethiopia. Dr. Thesis, Universty Nat. Resour. Life Sci. Vienna.

Mueller, J.P., Rischkowsky, B., Haile, A., Philipsson, J., Mwai, O., Besbes, B., Valle Zárate, A., Tibbo, M., Mirkena, T., Duguma, G., Sölkner, J., Wurzinger, M., 2015. Community-based livestock breeding programmes: Essentials and examples. J. Anim. Breed. Genet. 132, 155-168.

Netsanet Zergaw. 2014. On-farm phenotypic characterization and performance evaluation of Central Highland and Woyto-Guji goat types for designing community-based breeding strategies in Ethiopia, M.Sc thesis. Haramaya University, Ethiopia

Oseni, S., Bebe, O., 2010. Climate change, genetics of adaptation and livestock production in low input systems. 2nd Int. Conf. Clim. Sustain. Dev. Semi-arid Reg. August 16 - 20, 2010, Fortaleza - Ceará, Brazil.

R Development Core Team, 2013. R: A language and environment for statistical computing. R Foundation for Statistical Computing, Vienna, Austria.

Sölkner, J., Nakimbugwe, H., Zarate, A.V., 1998. Analysis of determinants for success and failure of village breeding programs.

Terfa, Z.G., Haile, A., Baker, D., Kassie, G.T., 2013. Valuation of traits of indigenous sheep using hedonic pricing in CentralEthiopia. Agric. Food Econ. 1, 1. 
399 Tsedeke Kocho., 2007. Production and marketing of sheep and goats in Alaba, Southern Nations, Nationalities and Peoples Region. M.Sc thesis. Hawassa University, Hawassa, Ethiopia.

401 Wilson, R.T. and Durkin, J.W., 1988. Small ruminant production in central Mali: reproductive performance in 402 traditionally managed goats and sheep. Livestock Production Science, 19, 523-529

403 Woldu, T., Markemann, A., Reiber, C., Kassie, G.T., Valle Zárate, A., 2016. Combining revealed and stated preferences to define goat breeding objectives in Ethiopia. Livest. Sci. 191, 179-186. 2016. Participatory definition of breeding objectives for sheep breeds under pastoral systems - the case of Red Maasai and Dorper sheep in Kenya. Trop. Anim. Health Prod. 48, 9-20. 


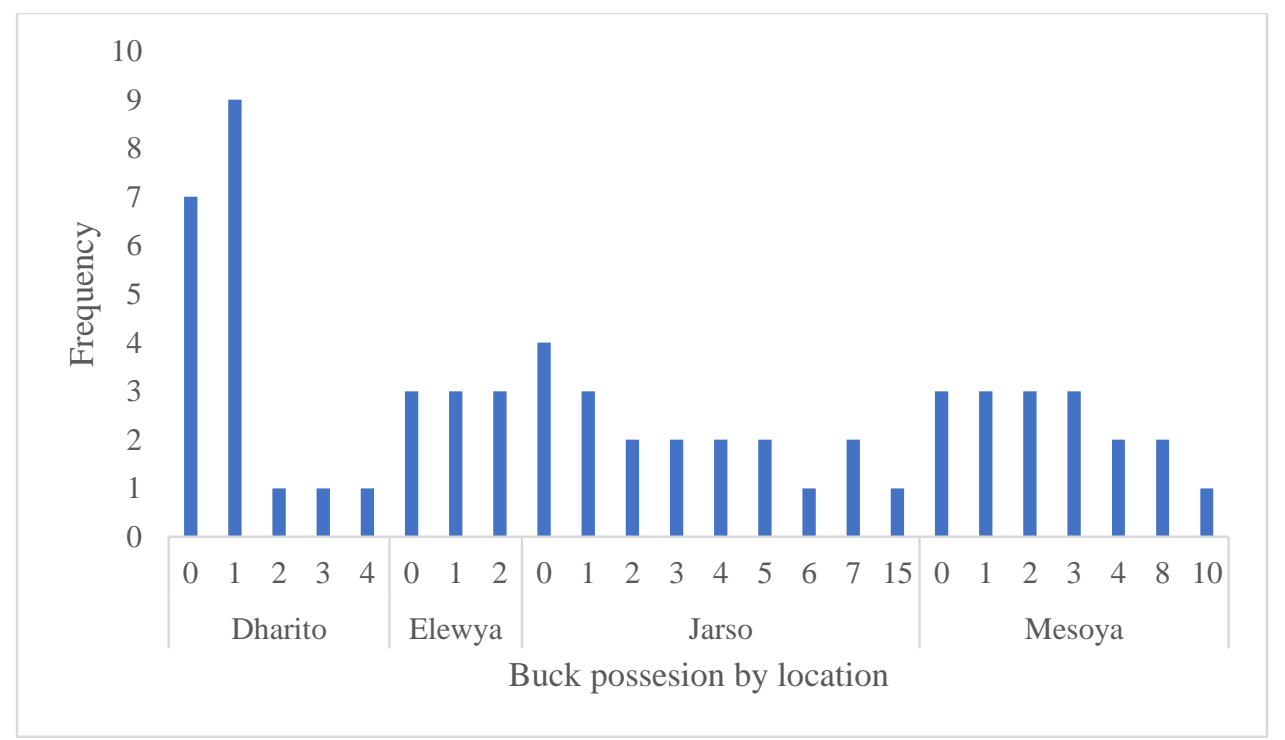

Figure 1. Frequency distribution of breeding buck possession in different locations. 
1 Table 1. Sampling details by village

\begin{tabular}{llcc}
\hline District & Village & $\begin{array}{c}\text { Respondent } \\
\text { households }\end{array}$ & Animals sampled \\
\hline Konso & Jarso & 19 & 72 \\
& Mesoya & 20 & 32 \\
Borena & Eleweya & 11 & 47 \\
& Dharito & 20 & 48 \\
\hline
\end{tabular}

2

3 Table 2. Frequency of major reason for the source of breeding does in different locations

\begin{tabular}{|c|c|c|c|c|c|c|}
\hline \multirow[t]{3}{*}{ Reasons } & \multicolumn{4}{|c|}{ Village } & \multirow{2}{*}{\multicolumn{2}{|c|}{$\begin{array}{l}\text { Chi } \\
\text { square P }\end{array}$}} \\
\hline & \multirow[t]{2}{*}{ Jarso } & \multirow[t]{2}{*}{ Mesoya } & \multirow[t]{2}{*}{ Elewya } & \multirow[t]{2}{*}{ Dharito } & & \\
\hline & & & & & Overall & value \\
\hline Selected based on performance & $8(44.6)$ & $10(66.7)$ & $5(55.6)$ & $11(61.1)$ & $34(54.8)$ & 0.096 \\
\hline Appeared as result of natural & $3(16.7)$ & $2(13.3)$ & $4(54.5)$ & $7(38.9)$ & $16(25.8)$ & \\
\hline \multicolumn{7}{|l|}{ selection } \\
\hline Purchased & $5(27.7)$ & $2(13.3)$ & $0(0)$ & $0(0)$ & $7(11.3)$ & \\
\hline Obtained as gift from parents & $2(11.0)$ & $1(6.7)$ & $0(0)$ & $0(0)$ & $5(8.1)$ & \\
\hline
\end{tabular}

$4 \quad$ Number in parenthesis are percentage for reasons within location

5

6

7 
9 Table 3. Pre-weaning kid survival as perceived by owners in different locations and seasons of the year

\begin{tabular}{|c|c|c|c|}
\hline Location & During good season & During dry season & During movement time \\
\hline Jarso & $96.1(4.64)^{a}$ & $59.4(5.37)^{\mathrm{ab}}$ & $64.8(8.70)$ \\
\hline Mesoya & $92.2(4.64)^{\mathrm{ab}}$ & $62.2(5.06)^{b}$ & $73.9(8.70)$ \\
\hline Elweya & $88.3(4.92)^{\mathrm{ab}}$ & $54.4(5.06)^{\mathrm{ab}}$ & $61.3(9.23)$ \\
\hline Dharito & $78.4(3.19)^{\mathrm{b}}$ & $42.4(3.49)^{\mathrm{a}}$ & $56.1(6.15)$ \\
\hline$P$-value & 0.0122 & 0.00723 & 0.421 \\
\hline
\end{tabular}

10 Values with different superscript letters within column are significantly different at $P=0.05$.

11

12 Table 4. Frequency of breeding buck availability in different location

\begin{tabular}{|c|c|c|c|c|}
\hline Location & Yes & No & Chi square & $\mathrm{P}$ \\
\hline Overall & $47(73.4)$ & $17(26.6)$ & 2.229 & 0.5262 \\
\hline Eleweya & $6(66.7)$ & $3(33.3)$ & & \\
\hline Jarso & 15 (78.9) & $4(21.1)$ & & \\
\hline Mesoya & $14(82.4)$ & 3 (17.6) & & \\
\hline Dharito & $12(63.2)$ & 7 (36.8) & & \\
\hline
\end{tabular}

13 Number in parenthesis are percentage values

14

15

16

17 
18 Table 5. Frequency of flocks herded separately versus mixed and average number of flocks mixed together in

19 permanent place and new place

\begin{tabular}{|c|c|c|c|c|c|}
\hline Location & Herded & Mixed with other & Chi square & $P$ & Number of flocks \\
\hline & separately & flock & & & mixed \\
\hline In permanent place & & & 12.54 & 0.05 & \\
\hline Jarso & $12(63.1)$ & $7(36.8)$ & & & 8.0 \\
\hline Mesoya & $11(64.7)$ & $6(35.3)$ & & & 4.5 \\
\hline Elewya & $3(33.3)$ & $6(66.7)$ & & & 3.5 \\
\hline Dharito & $5(26.3)$ & $14(73.7)$ & & & 2.8 \\
\hline In new place & & & 15.726 & 0.0153 & \\
\hline Jarso & $10(58.8)$ & $7(41.2)$ & & & 8.0 \\
\hline Mesoya & $2(15.4)$ & $11(85.6)$ & & & 5.7 \\
\hline Elewya & $1(12.5)$ & $7(87.5)$ & & & 3.6 \\
\hline Dharito & $9(47.4)$ & $10(52.6)$ & & & 7.3 \\
\hline
\end{tabular}

20 Number in bracket are percentage values

21 Table 6. Interest to share bucks in different villages

\begin{tabular}{|c|c|c|c|c|}
\hline Village & No & Yes & Chi square & P-value \\
\hline Jarso & $9(47.3)$ & $10(52.6)$ & 12.14 & 0.058 \\
\hline Mesoya & $8(50)$ & $8(50)$ & & \\
\hline Elewya & $0(0)$ & $9(100)$ & & \\
\hline Dharito & $5(27.8)$ & $13(72.2)$ & & \\
\hline
\end{tabular}

22

23

24 
25 Table 7. Ranking of breeding objective traits for goat in different locations

\begin{tabular}{|c|c|c|c|c|c|c|}
\hline \multirow[t]{2}{*}{ Trait of interest } & \multicolumn{4}{|c|}{ Ranking index (rank) } & \multirow{2}{*}{$\begin{array}{l}\text { Chi- } \\
\text { square }\end{array}$} & \multirow[t]{2}{*}{$\mathrm{P}$ value } \\
\hline & Jarso & Mesoya & Elewya & Dharito & & \\
\hline Growth & $0.26(1)$ & $0.21(2)$ & $0.25(1)$ & $0.24(1)$ & 20.08 & 0.1689 \\
\hline Survival & $0.07(5)$ & $0.16(4)$ & $0.14(5)$ & $0.13(5)$ & 29.41 & 0.01425 \\
\hline Reproduction & $0.24(2)$ & $0.20(3)$ & $0.19(3)$ & $0.22(3)$ & 20.56 & 0.1514 \\
\hline \multicolumn{7}{|l|}{ lambing and litter size) } \\
\hline Coat colour & $0.17(4)$ & $0.10(6)$ & $0.23(2)$ & $0.23(2)$ & 35.66 & 0.00198 \\
\hline Milk yield & $0.24(2)$ & $0.23(1)$ & $0.17(4)$ & $0.18(4)$ & 21.61 & 0.1185 \\
\hline Behavioral & $0.004(6)$ & $0.11(5)$ & $0.02(6)$ & $0.01(6)$ & 20.01 & 0.006694 \\
\hline
\end{tabular}

26

27

28

29

30

31

32

33

34

35

36 
37 Table 8. Influence of body condition score, fertility and survival on ranking decision

\begin{tabular}{|c|c|c|c|}
\hline Rank & $\begin{array}{c}\text { Body condition } \\
\text { score }\end{array}$ & Twining rate & $\begin{array}{c}\text { Pre-weaning kid } \\
\text { survival }\end{array}$ \\
\hline Overall & $3.2 \pm 0.04$ & $1.22 \pm 0.03$ & $80.6 \pm 2.22$ \\
\hline $\mathrm{CV}(\%)$ & 15.92 & 26.12 & 37.14 \\
\hline Doe rank & $<0.0001$ & 0.006 & $<0.0001$ \\
\hline First & $3.5 \pm 0.07^{\mathrm{a}}$ & $1.24 \pm 0.04^{\mathrm{a}}$ & $92.1 \pm 4.01^{\mathrm{a}}$ \\
\hline Second & $3.3 \pm 0.07^{\mathrm{ab}}$ & $1.14 \pm 0.04^{\mathrm{ab}}$ & $87.0 \pm 4.02^{\mathrm{a}}$ \\
\hline Third & $3.2 \pm 0.08^{\mathrm{b}}$ & $1.10 \pm 0.04^{\mathrm{ab}}$ & $83.9 \pm 4.37^{\mathrm{a}}$ \\
\hline Last & $2.7 \pm 0.08^{c}$ & $1.08 \pm 0.04^{\mathrm{b}}$ & $59.6 \pm 4.48^{\mathrm{b}}$ \\
\hline Village & $<0.0001$ & 0.045 & NS \\
\hline Jarso & $3.3 \pm 0.49^{\mathrm{a}}$ & $1.20 \pm 0.035^{\mathrm{a}}$ & $74.8 \pm 0.04$ \\
\hline Mesoya & $3.6 \pm 0.71^{\mathrm{a}}$ & $1.08 \pm 0.053^{\mathrm{ab}}$ & $86.8 \pm 0.56$ \\
\hline Eleweya & $3.1 \pm 0.49^{\mathrm{b}}$ & $1.07 \pm 0.044^{\mathrm{b}}$ & $76.4 \pm 0.05$ \\
\hline Dharito & $3.0 \pm 0.58^{\mathrm{b}}$ & $1.14 \pm 0.038^{\mathrm{ab}}$ & $84.6 \pm 0.39$ \\
\hline
\end{tabular}

$38 \quad \mathrm{a}, \mathrm{b}, \mathrm{c}$ Means within column with different superscripts are significantly different at $\mathrm{p}<0.05$

39

40

41

42

43

44 
45 Table 9. Least squares means \pm standard error for kid growth, milk yield and kidding interval score on by doe 46 ranking

\begin{tabular}{|c|c|c|c|c|}
\hline Rank & $\mathrm{N}$ & $\begin{array}{l}\text { Kid growth } \\
\text { score }\end{array}$ & Milk yield score & $\begin{array}{l}\text { Kidding } \\
\text { interval score }\end{array}$ \\
\hline First & 53 & $2.96^{\mathrm{a}}$ & $2.94^{\mathrm{a}}$ & 2.64 \\
\hline Second & 53 & $2.84^{\mathrm{a}}$ & $2.88^{\mathrm{a}}$ & 2.62 \\
\hline Third & 46 & $2.35^{b}$ & $2.47^{\mathrm{b}}$ & 2.57 \\
\hline Last & 46 & $1.46^{\mathrm{c}}$ & $1.33^{c}$ & 2.00 \\
\hline Kruskal-Wallis chi-squared & & 106.61 & 109.37 & 6.96 \\
\hline $\mathrm{P}$ value & & $<0.0001$ & $<0.0001$ & 0.07311 \\
\hline
\end{tabular}

$47 \quad$ a,b,c Means within column with different superscripts are significantly different at $\mathrm{p}<0.05$

48

49

50

51

52

53

54

55

56

57 
58 Table 10. Least squares means \pm standard error for body weight, linear body measurements and price of does in

59 Ethiopian Birr by doe rank and village

\begin{tabular}{|c|c|c|c|c|c|c|c|}
\hline $\begin{array}{l}\text { Rank/Villag } \\
\mathrm{e}\end{array}$ & Body weight & Body length & Chest girth & $\begin{array}{l}\text { Height at } \\
\text { wither }\end{array}$ & Ear length & Horn length & $\begin{array}{l}\text { Willingness } \\
\text { to pay (ETB) }\end{array}$ \\
\hline Overall & $31.2 \pm 0.35$ & $62.0 \pm 0.33$ & $74.4 \pm 0.30$ & $63.7 \pm 0.27$ & $13.3 \pm 0.09$ & $8.1 \pm 0.29$ & $1555 \pm 22.6$ \\
\hline $\mathrm{CV}(\%)$ & 15.2 & 7.27 & 5.52 & 5.79 & 9.25 & 48.87 & 18.08 \\
\hline Doe rank & $<0.0001$ & $<0.0001$ & $<0.0001$ & $<0.0001$ & $<0.0254$ & NS & $<0.0001$ \\
\hline First & $33.6 \pm 0.88^{a}$ & $65.2 \pm 0.78^{\mathrm{a}}$ & $76.6 \pm 0.74^{\mathrm{a}}$ & $63.8 \pm 0.72^{\mathrm{a}}$ & $13.7 \pm 0.25^{\mathrm{a}}$ & $8.8 \pm 0.55$ & $1367 \pm 46.5^{\mathrm{a}}$ \\
\hline Second & $31.3 \pm 0.89^{a}$ & $64.0 \pm 0.78^{a}$ & $74.3 \pm 0.74^{\mathrm{ab}}$ & $63.3 \pm 0.72^{\mathrm{a}}$ & $13.3 \pm 0.25^{\mathrm{ab}}$ & $8.5 \pm 0.53$ & $1272 \pm 1.4^{\mathrm{ab}}$ \\
\hline Third & $30.9 \pm 0.96^{a}$ & $63.1 \pm 0.86^{a}$ & $73.6 \pm 0.81^{b}$ & $63.0 \pm 0.79^{\mathrm{a}}$ & $13.3 \pm 0.23^{\mathrm{ab}}$ & $8.0 \pm 0.60$ & $1145 \pm 44.0^{\mathrm{b}}$ \\
\hline Last & $25.2 \pm 0.93^{\mathrm{b}}$ & $58.4 \pm 0.85^{b}$ & $68.0 \pm 0.80^{c}$ & $59.0 \pm 0.79^{b}$ & $12.7 \pm 0.25^{b}$ & $7.5 \pm 0.63$ & $833 \pm 46.9^{c}$ \\
\hline Village & $<0.0001$ & 0.00024 & 0.00072 & 0.00057 & 0.0056 & $<0.0001$ & $<0.0001$ \\
\hline Jarso & $27.3 \pm 0.59^{a}$ & $60.4 \pm 0.51^{\mathrm{a}}$ & $71.3 \pm 0.49^{\mathrm{a}}$ & $60.6 \pm 0.48^{a}$ & $12.8 \pm 0.15^{\mathrm{a}}$ & $8.3 \pm 0.36^{\mathrm{a}}$ & $971 \pm 30.1^{\mathrm{a}}$ \\
\hline Mesoya & $31.0 \pm 0.85^{b c}$ & $62.8 \pm 0.78^{b}$ & $74.6 \pm 0.74^{\mathrm{b}}$ & $61.8 \pm 0.73^{\mathrm{a}}$ & $13.1 \pm 0.23^{\mathrm{ab}}$ & $11.5 \pm 0.57^{b}$ & $1363 \pm 37.6^{b}$ \\
\hline Eleweya & $32.5 \pm 1.09^{\mathrm{cd}}$ & $64.7 \pm 0.97^{b}$ & $75.1 \pm 0.57^{b}$ & $64.6 \pm 0.90^{\mathrm{b}}$ & $13.8 \pm 0.28 b^{c}$ & $4.8 \pm 0.66^{\mathrm{c}}$ & $1129 \pm 47.8^{c}$ \\
\hline Dharito & $33.6 \pm 0.60^{\mathrm{d}}$ & $62.0 \pm 0.58^{b}$ & $76.3 \pm 0.53^{b}$ & $66.9 \pm 0.48^{b}$ & $13.9 \pm 0.16^{\mathrm{c}}$ & $6.5 \pm 0.48^{\mathrm{c}}$ & NA \\
\hline
\end{tabular}

$60 \quad$ a,b,c Means within column with different superscripts are significantly different at $\mathrm{p}<0.05$; ETB = Ethiopian Birr; 1

$61 \mathrm{USD}=28.40 \mathrm{ETB}$.

62

63

64

65

66 
67 Table 11. Spearman's correlation coefficient of doe rank with doe size, production, reproduction and morphological

68 traits in different locations

\begin{tabular}{|c|c|c|c|c|}
\hline \multirow[t]{2}{*}{ Traits } & \multicolumn{4}{|c|}{ Spearman's correlation with doe rank in different locations } \\
\hline & Jarso & Mesoya & Eleweya & Overall \\
\hline Doe body condition score & $0.43 * * *$ & $0.41 *$ & $0.34 *$ & $0.46 * * *$ \\
\hline Kidding interval score & $0.24 \mathrm{~ns}$ & $0.15 \mathrm{~ns}$ & & $0.2 *$ \\
\hline Twining rate & $0.45^{* * *}$ & $0.21 \mathrm{~ns}$ & $0.38 * *$ & $0.4 * * *$ \\
\hline Kid pre-weaning survival & $0.18 \mathrm{~ns}$ & $0.06 \mathrm{~ns}$ & $0.33^{*}$ & $0.21 * *$ \\
\hline Kid growth & $0.67 * * *$ & $0.58 * * *$ & $0.74 * * *$ & $0.72 * * *$ \\
\hline Milk yield score & $0.62 * * *$ & $0.61^{* * *}$ & $0.72 * * *$ & $0.69 * * *$ \\
\hline Doe price & $0.66^{* * * *}$ & $0.65^{* * *}$ & $0.73 * * *$ & $0.56 * * *$ \\
\hline Body length & $0.45^{* * *}$ & $0.34 \mathrm{~ns}$ & $0.53 *$ & $0.41 * * *$ \\
\hline Chest girth & $0.56^{* * * *}$ & $0.38^{*}$ & $0.77 * * *$ & $0.52 * * *$ \\
\hline Height at wither & $0.27 *$ & $0.08 \mathrm{~ns}$ & $0.81^{* * *}$ & $0.29 * *$ \\
\hline Ear size & $0.31 * *$ & $0.09 \mathrm{~ns}$ & $0.28 \mathrm{~ns}$ & $0.22 *$ \\
\hline Horn size & $0.37 * *$ & $0.23 \mathrm{~ns}$ & $-0.28 \mathrm{~ns}$ & $0.24 *$ \\
\hline Body weight & $0.49 * * *$ & $0.35 \mathrm{~ns}$ & $0.85 * * *$ & $0.48 * * *$ \\
\hline
\end{tabular}

69

$* * *=<0.001, * *=<0.01, * * *=<0.05, \mathrm{~ns}=$ non-significant

70

71

72

73

74 
75 Table 12. Pairwise Spearman's rank correlation among selected variables (upper diagonal) and associated P values

76 (below diagonal)

\begin{tabular}{lccccccc}
\hline & KI & TR & SP & KGS & MY & CG & BWT \\
\hline Kidding interval (KI) & & 0.01 & 0.07 & 0.31 & 0.29 & 0.18 & 0.27 \\
Twining rate (TR) & 0.8754 & & -0.05 & 0.26 & 0.27 & 0.36 & 0.45 \\
Survival proportion (SP) & 0.4940 & 0.4913 & & 0.14 & 0.19 & 0.21 & 0.17 \\
Kid growth score (KGS) & 0.0019 & 0.0004 & 0.0596 & & 0.78 & 0.39 & 0.39 \\
Milk yield (MY) & 0.0046 & 0.0002 & 0.0088 & 0.0000 & & 0.47 & 0.51 \\
Chest girth (CG) & 0.0771 & 0.0000 & 0.0214 & 0.0000 & 0.0000 & & 0.79 \\
Body weight (BWT) & 0.01003 & 0.0000 & 0.0723 & 0.0001 & 0.0000 & 0.0000 & \\
\hline
\end{tabular}


